Issues in Information Systems

Volume 18, Issue 3, pp. 19-28, 2017

\title{
A CONSTRUCTIVE TEAM PROJECT MODEL FOR ONLINE CYBERSECURITY EDUCATION
}

\author{
Ping Wang, Robert Morris University, wangp@rmu.edu \\ Raed Sbeit, Verizon, raed.sbeit@verizonwireless.com
}

\begin{abstract}
Cybersecurity has become a fast-growing career field and program of study for higher education. Teamwork ability with skills for successful collaboration is among the top ranked qualifications for cybersecurity professionals. Team projects with group work for online collaborative learning can be an effective educational activity for building teamwork competency. There are barriers and challenges to successful online learning and virtual team collaboration. This paper proposes a new constructive team project model for online cybersecurity education based on the Online Learning Community Model. The team project model highlights the team formation and development process, sense of community, motivation, teaching presence, and assessment as constructive factors for collaborative learning and developing effective teamwork skills. Preliminary data on assessment results and observations on student performance in sample team projects from an online graduate cybersecurity program in the United States indicate consistent effectiveness of the proposed model.
\end{abstract}

KEYWORDS: Cybersecurity, team project, collaborative learning, online learning community, assessment

\section{INTRODUCTION}

Cybersecurity, traditionally known as information security, is a fast-growing career field and an important area with increasing demand and opportunities for higher education. Cybersecurity is defined by NICCS (National Initiative for Cybersecurity Careers and Studies) under the U.S. Department of Homeland Security as "The activity or process, ability or capability, or state whereby information and communications systems and the information contained therein are protected from and/or defended against damage, unauthorized use or modification, or exploitation" (NICCS, 2017, c section, para.29). Information security analyst is just one of the commonly known cybersecurity career titles. According to U.S. Department of Labor Bureau of Labor Statistics (BLS), employment of information security analysts is projected to grow $18 \%$ from 2014 to 2024 , much faster than the average growth rates of $7 \%$ for all occupations and $12 \%$ for all computer related occupations (U.S. Department of Labor, 2015).

Teamwork competency and skills are an important qualification for the cybersecurity workforce. Recognition of the importance of teamwork by both educators and students is requisite for implementing successful teamwork activities. In addition to technical skills or hard skills needed for technology related career fields like Cybersecurity, soft skills such as teamwork, communication, and work ethics are among the top soft skills needed for success in today's workplace. Teamwork attributes, such as being cooperative, agreeable, getting along with others, supportive, helpful, and collaborative, are among the top job skills desired by employers and should be emphasized in college curricula (Robles, 2012). The ability to function effectively on teams to accomplish a common goal is one of the student outcomes for graduation and one of the criteria for computing program accreditation (ABET, 2015). Teamwork is especially important to cybersecurity education. Teamwork is listed as the number one cybersecurity workplace competency in the Cybersecurity Industry Model published by the U.S. Department of Labor (2014). (ISC) ${ }^{2}$, International Information System Security Certification Consortium, has recommended that higher education institutions provide opportunities to develop and assess teamwork skills in addition to technical and problem-solving skills (2014). The ability to collaborate and partner effectively with teams is an essential trait for cybersecurity workers to succeed (Thibodeaux, 2016).

Online or distance education is a promising environment for teamwork competency development as online learning has become a significant delivery modality in higher education with steady growth. The latest report on tracking online 
education in the United States shows that a total of 5.8 million or $28 \%$ of college student population were taking some of their courses online at a distance in fall 2014 with a 7\% increase over fall 2012; it also shows that many institutions are continuing to add and grow online programs in spite of declining campus-based enrollments (Allen, Seaman, Poulin, \& Straut, 2016). Online education brings great potential for collaborative learning for teams or smaller groups of students beyond the bounds of time and distance due to the technical capacities for remote communication, virtualization, and asynchronous participation. However, there are also challenges. For example, there are barriers to implementing virtual teams and groups for successful collaboration in team formation and development, motivation for teamwork, team and individual assessment, and conflict management (Chiong \& Jovanovic, 2012; Ebrahim, Ahmed, \& Taha, 2009; Lilian, 2013; Roberts \& McInnerney, 2007).

The terms teamwork and group work are used interchangeably in this paper. It is encouraging that the preliminary research by Angelo and McCarthy (2016) indicated that students with high exposure to virtual group assignments performed significantly better in business education than students with low or no exposure to group assignments. However, there has been little research on effective models of teamwork for collaborative learning in online cybersecurity education. This paper is to propose a constructive team project model to address the question of how to design, manage, and assess cybersecurity team projects for effective collaborative learning in an online environment. The proposal is based on a tested online learning community model and empirical data on sample virtual team projects from graduate level cybersecurity classes at a regionally accredited university in the United States. The following sections of this paper will review relevant theoretical background on collaborative learning and virtual team management and assessment, formulate and explain the proposed model, describe the research methodology, and present and discuss the assessment results and observations from the sample team project experience. The paper will conclude with practical implications and suggestions for further study.

\section{BACKGROUND}

This section reviews relevant theoretical background and research literature on collaborative learning, team formation and development, motivation for team work, and online learning community so as to inform the development of a constructive online team project model for cybersecurity education.

\section{Collaborative Learning}

The primary goal of teamwork in education is to maximize collaborative learning through activities in groups. Collaborative learning is "an educational approach to teaching and learning that involves groups of learners working together to solve a problem, complete a task, or create a product" (Laal \& Laal, 2011, p.491). The size of the groups can be a pair, a small group of 3 to 5 , a community or a society of millions of learners, and working together may include face-to-face or computer-mediated online interactions in either synchronous or asynchronous mode (Dillenbourg, 1999). Computer-mediated online collaborative learning with incorporation of information technology for communication and interaction may lead to enhanced learning outcomes and learning experience (Alavi, 1994). The group size for this study will be small groups of 3 to 5 learners in master's level cybersecurity classes, and the mode of interaction is online and asynchronous.

The social constructivist philosophy is that learning is a social process of interaction and that individuals take responsibility for their own learning actions and respect the abilities and contributions of their peers and group members. Accordingly, collaborative learning may lead to numerous benefits for teaching and learning, which include positive student attitude and engaging learning environment, higher student esteem and motivation, and better results in critical thinking and problem solving (Laal \& Ghodsi, 2012; Lin, 2015; Pantiz, 1999). There are five essential conditions for group collaborative learning to be successful and more productive than individual learning efforts: (1) positive interdependence - share a common positive goal of success in learning and unite all efforts around the common goal; (2) promotive interaction - trust and help each other to reach group goals;(3) individual accountability - member responsibility to contribute his or her fair share to the group's success with no "free ride"; (4) interpersonal skills - accept and support each other with effective communication and constructive conflict resolution; and (5) group processing - reflect on member behavior and actions and seek improvements for the group (Johnson \& Johnson, 1994; Laal, Laal, \& Kermanshahi, 2012). 


\section{Team Formation and Development}

The team or group formation process is essential to successful team work. Roberts and McInnerney (2007) highlighted team or group formation as one of the most significant challenges for online group learning. One option is to allow students to form their own groups based on Tuckman's four stages of group development from dependency to interdependence: (1) forming - getting acquainted and establishing goals and rules; (2) storming - experiencing disagreement over priorities and developing relationships; (3) norming - establishing trust, reaching consensus on leadership and member roles, and setting standards and objectives; and (4) performing - demonstrating mutual help and flexibility and successful team performance to complete the project task (Gražulis, 2012; Largent, 2016; Richards, 2009; Tuckman and Jensen, 1977). It may be beneficial to allow students to choose a group of their preference for a short-term group project that lasts a few weeks, but there could be lack of diversity and less experience for students to learn how to work with unfamiliar people (Redmond, 2001; Richards, 2009).

Alternatively, either random selection of team members or intentional assignment of members into heterogeneous groups considering various factors can be used in team formation, but the random selection method for team formation is more simplified and proven to be as effective as more sophisticated approaches (Chiong \& Jovanovic, 2012; Roberts \& McInnerney, 2007). A random selection or pseudo-random selection based on a numerical or alphabetical order for group membership should be sufficient and easy to implement for the online class environment given the insignificance of meeting time and location for team collaboration with online and asynchronous communication (Roberts \& McInnerney, 2007).

\section{Motivation for Teamwork}

The main goal of collaborative learning through teamwork is to enable team members to reach their maximum potential toward achieving their common goal of learning by constructing and sharing knowledge. Motivating team members to do their best is one of the challenges in online team projects. Maslow's Hierarchy of Needs has been a positive human motivation theory, and certain elements of the theory may be applicable to educational motivation. The human need to know and understand and the need for self-actualization in the upper level growth needs of Maslow's hierarchy of needs can be positive motivating force in teamwork. The human need for self-actualization is at the top of the hierarchy and represents an individual desire to realize his or her full potential talents and capabilities (Maslow, 1943). This individual desire for success may be used positively and constructively in the team environment to achieve joint success in teamwork.

Individual motivation must be coordinated within a team community to minimize conflict and maximize team harmony and productivity. Motivation in virtual teamwork environment derives from the extent of team cohesion and the amount of trust and confidence among team members (Zaccaro \& Bader, 2003). Team projects in education are supposed to simulate a real world community of practice with professional interactions and knowledge sharing and knowledge creation in order provide students with realistic teamwork experience and skills. Therefore, members of a team project should acquire a sense of community and develop interpersonal trust and cohesion within the team community. Such sense of community and interpersonal trust and cohesion will lead to mutual acceptance of knowledge sharing (Nistor, Daxecker, Stanciu, \& Diekamp, 2015).

\section{Online Learning Community}

Constructing a motivating and engaging online community with asynchronous participation is critical for successful collaborative online learning and development of critical thinking and achievement of higher learning (Swan, Shen, \& Hiltz, 2006; Wang, 2015). The Community of Inquiry (CoI) model proposes a conceptual framework with three interacting elements for successful online learning with computer-mediated communication. The three core elements in the CoI model with positive and constructive categories and activities for community building are: (1) cognitive presence - constructing meaning through sustained communication including information exchange and connecting ideas; (2) social presence - projecting personal characteristics into community with open communication seeking group cohesion and encouraging collaboration; and (3) teaching presence - designing educational experience and providing facilitation and instructions (Garrison, Anderson, Archer, 2000; Garrison \& Arbaugh, 2007; Wang, 2015). 
While the cognitive presence element in the Community of Inquiry (CoI) model also helps to motivate higher-order thinking skills and collaborative work through online communication, the social presence element is the most valuable contribution of the CoI model because it interacts with cognitive presence and teaching presence and helps to create a constructive online environment to motivate collaborative learning (Wang, 2015). Garrison, Anderson, and Archer (2000) emphasized the role of the social presence element in generating constructive affective factors such as being responsive, respectful, and supportive whereas "cognitive presence by itself is not sufficient to sustain a critical community of learners. Such an educational community is nurtured within the broader social and emotional environment of the communicative transaction" (p.94). In addressing the effectiveness of asynchronous online discussion assignments, Wang (2015) proposed a new constructive Online Learning Community model based on the Community of Inquiry model and demonstrated with empirical success that a constructive online learning model should include and emphasize the important role of assessment in evaluating and motivating students' learning and that social presence and cognitive presence should be incorporated into the assessment of learning activities to make online learning experience successful, enjoyable, and sustainable.

\section{ONLINE TEAM PROJECT MODEL}

The teamwork model proposed by this paper is primarily based on the Online Learning Community Model by Wang (2015) with adaptations for online team projects. The Online Learning Community Model, adapted from the Community of Inquiry learning model, includes the key elements of cognitive presence, social presence, teaching presence, and assessment presence. Figure 1 below shows the Online Learning Community Model and its components.

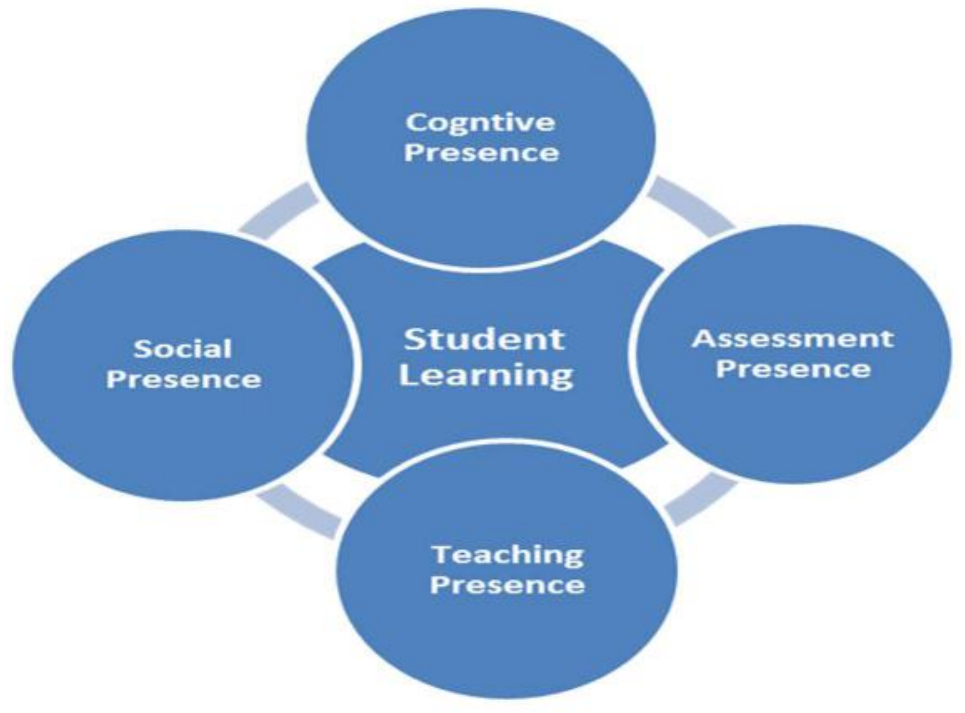

Figure 1. Online Learning Community Model (Wang, 2015)

The rationale for the selection of the Online Learning Community Model for this paper is the model's focus on student learning and online collaboration and its emphasis on assessment of student learning outcomes. Proficiency in teamwork and collaborative problem solving is essential for the 21 st century workforce and education, but it is a challenge to assess or evaluate group collaboration and individual members of a group (Nihalani \& Robinson, 2012). Online team projects are suitable group assignments for students to learn, practice, and enhance their problem solving and communication skills. While all the presence elements in the Online Learning Community Model are interrelated and contribute to student learning, the assessment presence includes constructive components and activities, such as evaluation, grading, feedback, recommendations, expectations, rubric, and scoring criteria. The assessment presence has positive impact on instructor teaching presence, student cognitive presence for learning, and student social presence for group communication and collaboration (Wang, 2015).

The Online Learning Community Model was intended to address asynchronous online discussion assignments. The following adaptations are needed for the model to be used for team project assignments. First of all, team formation 
and development process and rules should be simple, random, and objective. A more simplified way for team development with fewer avoidable difficulties will benefit students in having a more rewarding teamwork experience (Largent, 2016). For a regular semester team or group project, the ideal size should be around 3 to 5 per group. The team memberships should be assigned alphabetically by student last name, student number, or a certain hashing algorithm, without considering student personal preferences for working with buddies. This random or pseudo-random team formation method is simplified, objective, and free from personal preferences or bias from the students or the instructor, and can be as effective as more sophisticated team formation and development (Roberts \& McInnerney, 2007). The random team formation method will benefit student learning experience by providing more heterogeneous teammates with more diverse background experience and perspectives, which resembles or is close to resemblance to the diversity in real workplace.

Secondly, the teaching presence in the Online Learning Community Model should emphasize instructor monitoring and management of the teamwork process for each group. The instructor should design and communicate the team project plans, instructions, outcomes, and expectations clearly. To be proactive and facilitating, the instructor should require each team to have a teamwork plan with an outline of progress schedule, milestones, and team leadership and specified roles for each member within the first quarter of the teamwork duration. In addition, the instructor should monitor the team activities and communication such as discussions for each group and provide necessary feedback and guidance as well as to sense, detect, and prevent or resolve any interpersonal conflicts within each group.

Last but not least, the assessment presence in the Online Learning Community Model should include evaluation of both teamwork and individual participation and contributions. The instructor should include clear expectations and grading rubrics and any team and individual penalties or bonus rewards such as those used by Nihalani and Robinson (2012). The assessment measures should motivate team members to do their best collaboratively as a team and encourage each member to reach his or her best potential. Team members should be made aware that the individual grade may vary and differ from the teamwork grade based on individual participation and contribution record as well as peer reviews from teammates. The peer reviews should include ratings and specific comments on each team member on the aspects of participation, contribution, collegiality, and communication that are critical to the team success. The peer reviews should be made confidential and submitted privately to the instructor only in order to maintain honesty and integrity of the review data.

\section{METHODOLOGY}

To test the adapted Online Learning Community Model for team projects, this study observes and examines the team project activities, rubrics, results of assessment, and student peer reviews and comments for an asynchronous online team project used for three classes (for a total of 74 participating students) of a graduate level cybersecurity technology course in three different semesters from summer 2016 to spring 2017 at a regionally accredited university in the United States. The course is an in-depth study of the theory and practice of intrusion detection and prevention in cyberspace. The course topics include network security, monitoring, auditing, intrusion detection, intrusion prevention, and ethical penetration testing. The course learning outcomes emphasize application and critical assessment of measures, techniques, and tools in identifying system vulnerabilities and threats and in preventing cyber attacks. The course is delivered asynchronously online as the students are mostly working professionals and military service members located in different states in the U.S. and around the world in various time zones.

The team project is one of the required assignments for this course and makes up a significant $20 \%$ of the student's course grade. The team assignment instructions are updated and posted at the beginning of each semester. The team assignment is a collaborative project asking each group to complete an in-depth research report on a certain cybersecurity technology issue to present findings that include a background introduction, components of the technology and how they work, survey of research on the vulnerabilities and solutions, applications of the technology and assessment of its strengths and weaknesses, and the future of the technology. The finished team product deliverable for the team project is a complete report paper that is APA compliant in format and will pass Turnitin academic integrity check. The learning outcomes for the project are primarily for students to demonstrate their knowledge and skills in the specified cybersecurity technology and its applications, their competency in research and 
critical thinking, and their ability to collaborate effectively in a small group or team environment. The contributions of all team members for this assignment are required to be posted in the team's group area in the online classroom. The team formation is pseudo-random as the team membership for each group is objectively assigned by the instructor according to the alphabetical order of students' last names as announced in the team formation rule in the project instructions. The team size is typically 4 or 5 . The team formation takes place a few weeks after the beginning of the semester and after all students have introduced themselves to the class and become acquainted with one another. Within two weeks after the team formation, each team is required to select a team leader and post an initial team plan to outline their work areas and items, progress schedule, milestones, and individual expertise, roles and contact information. Individuals on each team are required to communicate with their team and update their progress on a weekly basis. Students are encouraged to use the Group Discussion area for communication, but they may use other means of communication agreed to by all members of the team.

In terms of teaching presence in the online teamwork for collaborative learning, the instructor plays a very important role in guiding, monitoring, and facilitating the team project progress for all groups. To begin with, the instructor explains the value and importance of the teamwork and collaboration for the cybersecurity profession to help students cognitively understand and accept the value of collaboration. The instructor also makes it clear from the beginning that each student will be rewarded and graded according to the quality of their team product as well as their individual participation and contributions and peer review results. Students get the clear message that there is no free ride on this important project. The instructor also reviews the initial team plan and provides necessary feedback, recommendations, and useful resources to help each team to be on the right track. In addition, the instructor monitors the team member presence and communication on a regular basis to address student questions, provide positive reinforcement for good and healthy team and individual behavior while discouraging negative behavior affecting collegiality and team member relations.

In terms of assessment presence, a clear grading rubric for the team report product is posted. The rubric includes a fine-grained evaluation system of five different levels of rating and scoring with detailed corresponding performance indicators: Outstanding (95\%-100\%), Excellent (90\%-94\%), Good (80\%-89\%), Inadequate (50\%-80\%), Unacceptable (below $50 \%$ ). The ratings apply to both content areas ( $80 \%$ of team grade) and writing and format ( $20 \%$ of team grade). All students are also required to submit an individual peer review form at the end of the project to evaluate themselves and their teammates on a 1 (lowest) to 10 (highest) scale with supporting comments in these four areas with clear definitions: participation, contribution, collegiality, and communication. Participation is defined as attending all team meetings and participating in all group activities; Contribution is defined as contributing quality work with diligence, integrity, and responsibility; Collegiality is defined as treating teammates with respect and patience and a positive and cooperative attitude; Communication is defined as speaking and writing clearly and accurately. Students are asked to write comments to support their ratings as well. The individual peer reviews are emailed to the instructor privately to maintain the confidentiality of student answers and ratings of their peers. The data collected were processed and analyzed using Microsoft Excel. The following section presents and discusses relevant data and findings for the study.

\section{FINDINGS AND DISCUSSIONS}

\section{Team and Individual Assessment Results}

Student assessment results are direct indicators of student learning and the effectiveness of the online learning community. Table 1 below presents the average team grade, average individual grade, team success rate, and individual success rate for each of the three classes for this study.

Table 1. Summary of Team and Individual Assessment Results

\begin{tabular}{|l|c|c|c|c|c|c|}
\hline Semester/Class & N & N-T & Average-T & Average-I & Success-T & Success-I \\
\hline Summer 2016 & 24 & 5 & $92.02 \%$ & $92.68 \%$ & $100 \%$ & $100 \%$ \\
\hline Fall 2016 & 25 & 5 & $92.57 \%$ & $92.82 \%$ & $100 \%$ & $100 \%$ \\
\hline Spring 2017 & 25 & 5 & $93.08 \%$ & $93.76 \%$ & $100 \%$ & $100 \%$ \\
\hline
\end{tabular}


The $\mathrm{N}$ column represents total number of students for each class. The N-T column represents the number of groups or teams for each class; and the team size is mostly 5 members except for 1 team that has 4 members. The Average- $\mathrm{T}$ column shows the average team grade for each class in percentage scale. The Average-I column shows the average individual grade on the team assignment within each team in percentage scale. The Success-T and Success-I columns indicate the rate of success for each of the teams and individuals respectively within each class. The team grade is assessed using the team project rubric for both content and format areas, and the individual grade is based on the team grade, individual participation and contribution record, and peer review results. The expected score (in percentage scale) for success is $80 \%$ or higher. The Pearson correlation coefficient value between Average-T and Average-I is: $r=0.91$. The $r$ value indicates a strong positive bivariate correlation between the average team performance and average individual performance on this project. In addition, the high percentages of team success and individual success in the team assignment reflects the effectiveness of Online Learning Community Model used for collaborative learning through this team project assignment.

\section{Student Peer Review Results}

Student peer reviews are an important factor in motivating student collaboration and in individual assessment. Table 2 below presents the aggregate results on student peer reviews for the three classes.

Table 2. Summary of Student Peer Review Results

\begin{tabular}{|l|c|c|c|c|}
\hline Semester/Class & N & $\begin{array}{c}\text { Average } \\
\text { Reviews }\end{array}$ & Average-I & $\begin{array}{c}\text { Pearson } \\
\text { Correlation }(\boldsymbol{r})\end{array}$ \\
\hline Summer 2016 & 24 & 9.43 & $92.68 \%$ & 0.69 \\
\hline Fall 2016 & 25 & 9.29 & $92.82 \%$ & 0.81 \\
\hline Spring 2017 & 25 & 9.52 & $93.76 \%$ & 0.78 \\
\hline
\end{tabular}

Column $\mathrm{N}$ represents total number students for each class. Average Reviews is the average of reviews (on a scale of 1-10) for each student from his or her team members on participation, contribution, collegiality, and communication. The average value indicates a comprehensive perception from one's peers in the group. The Average-I is the average individual grade on the team project in each class. A student's actual individual grade on any item is confidential and visible only to the student. The Pearson correlation $r$ value is the bivariate correlation between the average peer review results for each student and the student's individual grade on the team project. The $r$ values $(0.69,0.81$, and 0.78$)$ are all statistically significant and indicate a strong correlation between a student's actual performance and team peer perceptions on the student's performance. The instruments used for Tables 1 and 2 include valid measures on student performance, which is the intended measure for the study. The high correlation values from the two sources of measures on student performance reflect strong convergent validity as defined by Sekaran (2003). In addition, it should be noted that two students, one from the fall 2016 class and the other from the spring 2017 class, had to withdraw about half way through the semester for personal reasons. However, both students voluntarily completed their participation in and contributions to the team project because they both stated that they did not want to disappoint their teammates. This is additional evidence of positive peer pressure for group collaboration.

\section{Student Perceptions on Online Learning Community}

Student perceptions on the elements of online learning community, such as instructor feedback, interactions with students, and quality of grading and assessment are found to be important to the improvement of online programs and courses that will benefit student learning (King, 2014; Russ \& Eastep, 2013; Wang, 2015). Table 3 below presents the results of students' evaluation and perceptions on the instructor and the online learning environment.

Table 3. Summary of Student Evaluations of Learning Community

\begin{tabular}{|l|c|c|c|c|c|}
\hline Semester/Class & $\boldsymbol{N}$ & $\begin{array}{c}\text { Fair } \\
\text { Grading }\end{array}$ & $\begin{array}{c}\text { Helpful } \\
\text { Feedback }\end{array}$ & $\begin{array}{c}\text { Student } \\
\text { Interaction }\end{array}$ & $\begin{array}{c}\text { Instructor } \\
\text { Overall }\end{array}$ \\
\hline Summer 2016 & 24 & 4.55 & 4.50 & 4.30 & 4.45 \\
\hline Fall 2016 & 25 & 4.60 & 4.45 & 4.46 & 4.54 \\
\hline Spring 2017 & 25 & 4.64 & 4.94 & 4.75 & 4.80 \\
\hline
\end{tabular}




\section{Issues in Information Systems \\ Volume 18, Issue 3, pp. 19-28, 2017}

Column N represents the size of each class. The student perceptions and evaluation categories are: Fair Grading, Helpful Feedback, Student Interaction, and Instructor Overall. The score range for each category is 0-5. The student evaluation results indicate very positive student perceptions and high ratings on the value of interaction with students (including group discussions and communication), on the assessment (including grading and feedback), and on the instructor overall. Positive perceptions from students on the social presence factors like student interactions and their high ratings on the instructor (key actor of teaching presence) and assessment presence (fair grading and helpful feedback) are indicators of an effective, positive, and constructive online learning community (Wang, 2015). The instrument and measures used for the data in Table 3 extracted from the university-wide standard class evaluation surveys have been tested and used for over 20 years with consistent validity and reliability.

\section{CONCLUSIONS}

Cybersecurity is a fast growing career field with increasing demand for workforce preparation. Teamwork ability is critical to professional success in Cybersecurity. Online cybersecurity education has been on the rise to accommodate working professionals and students across distance and time zones. This paper proposes a constructive team project model for online cybersecurity education based on the Online Learning Community Model with appropriate adaptations for team projects. The teamwork model highlights team formation and development process, sense of community and social presence, instructor teaching presence, and assessment presence as constructive factors for collaborative learning and effective teamwork skills.

Preliminary data from sample team projects at an online graduate cybersecurity program in the United States indicate consistent effectiveness of the proposed online teamwork model. The assessment results indicate a strong correlation between collaborative teamwork performance and individual performance on the project. The student peer review results show a strong correlation between a student's actual performance and team peer perceptions on the student's performance. The high correlations of the two measures on student performance indicate strong validity of the study. The findings have important implications for cybersecurity education and training. The study shows that teamwork projects can be an effective method for online teaching and learning with asynchronous participation of students in various physical locations. It is possible for team member to reach their best individual potential while contributing to a high quality collaborative team product. Teamwork can also be used to help build and maintain a positive and constructive online learning community.

Online education faces frequent innovations while cybersecurity education is emerging and evolving. There are future opportunities for further studies on online collaborative learning for cybersecurity education. This preliminary study is based on limited sample size available; future follow-up studies with more cumulative sample size would be more valuable to the validity and reliability of the research. It may also be valuable to focus on how students collaborate in teams on cyber offense and defense simulations in a virtual environment. Comparative studies on team projects between online and on-ground delivery modes should be useful. Given the importance of communication in education and professional careers, it should be valuable to study student online communication and its impact on collaborative learning on a cybersecurity technology subject.

\section{REFERENCES}

ABET. (2015). Criteria for accrediting computing programs (2016-2017 accreditation cycle). Retrieved from http://www.abet.org/accreditation/accreditation-criteria/criteria-for-accrediting-computing-programs-2016$2017 /$

Alavi, M. (1994). Computer-mediated collaborative learning: An empirical evaluation. MIS Quarterly, June 1994, 159-174.

Allen, I. E., Seaman, J., Poulin, R., \& Straut, T.T. (2016, February). Online report card: Tracking online education in the United States. Retrieved from http://onlinelearningsurvey.com/reports/onlinereportcard.pdf 
Angelo, R., \& McCarthy, R. V. (2016). Quantifying the optimum blend of group collaboration exercises to promote learning in virtual groups. Issues in Information Systems, 17(II), 105-114.

Chiong, R., \& Jovanovic, J. (2012). Collaborative learning in online study groups: An evolutionary game theory perspective. Journal of Information Technology Education: Research, 11(2012), 81-101.

Dillenbourg, P. (1999). What do you mean by ‘collaborative learning?’ In P. Dillenbourg (Ed.), Collaborativelearning: Cognitive and Computational Approaches (pp.1-19). Oxford, UK: Elsevier.

Ebrahim, N. A., Ahmed, S., \& Taha, Z. (2009). Virtual teams: A literature review. Australian Journal of Basic and Applied Sciences, 3(3), 2653-2669.

Garrison, D. R., Anderson, T., \& Archer, W. (2000). Critical inquiry in a text-based environment: Computer conferencing in higher education. Internet and Higher Education, 2(2-3), 87-105.

Garrison, D. R., \& Arbaugh, J. B. (2007). Researching the community of inquiry framework: Review, issues, and future directions. Internet and Higher Education, 10, 157-172.

Gražulis, V. (2012). Teamwork - the assumptions of the theoretical construct adaptation in organization activity (lithuanian case). Human Resources Management \& Ergonomics, VI (2/2012), 78-94.

$(\text { ISC) })^{2}$. (2014). Cybersecurity workforce competencies: Preparing tomorrow's risk-ready professionals. Retrieved from https://www.nationalcyberwatch.org/resource/cybersecurity-workforce-competencies-preparingtomorrows-risk-ready-professionals- $2 /$

Johnson, R. T. and Johnson, D. W. (1994). An overview of cooperative learning. In Thousand, J., Villa, A. \& Nevin, A. (Eds.), Creativity and collaborative learning (pp.2-21). Baltimore, MD, USA: Brookes Publishing.

King, S. B. (2014). Graduate student perceptions of the use of online course tools to support engagement. International Journal for the Scholarship of Teaching and Learning, 8(1). Retrieved from http://digitalcommons.georgiasouthern.edu/ij-sotl/vol8/iss1/5

Laal, M., \& Ghodsi, S. M. (2012). Benefits of collaborative learning. Procedia - Social and Behavioral Sciences, $31(2012), 486-490$.

Laal, M., \& Laal, M. (2011). Collaborative learning: What is it? Procedia - Social and Behavioral Sciences, 31(2012), 491-495.

Laal, M., Laal, M., \& Kermanshahi, Z. K. (2012). 21st century learning: Learning in collaboration. Procedia Social and Behavioral Sciences, 47(2012), 1696-1701.

Largent, D. L. (2016). Measuring and understanding team development by capturing self-assessed enthusiasm and skill levels. ACM Transactions on Computing Education, 16(2), 6:1-27.

Lilian, S. C. (2013). Virtual teams: Opportunities and challenges for e-leaders. Procedia - Social and Behavioral Sciences, 110(2014), 1251-1261.

Lin, L. (2015). Exploring collaborative learning: Theoretical and conceptual perspectives. In Investigating Chinese HE EFL Classrooms (pp.11-28). Berlin: Springer-Verlag. DOI 10.1007/978-3-662-44503-7_2.

Lipnack, J., \& Stamps, J. (1997). Virtual teams: Reaching across space, time, and organizations with technology. John Wiley and Sons.

Maslow, A. H. (1943). A theory of human motivation. Psychological Review, 50, 370-396. 
NICCS (National Initiative for Cybersecurity Careers and Studies). (2017). Explore terms: A glossary of common cybersecurity terminology. Retrieved from https://niccs.us-cert.gov/glossary

Nihalani, P. K., \& Robinson, D. H. (2012). Collaborative versus individual digital assessments. In Mayrath, M. C. (Ed.). Technology-Based Assessments for 21st Century Skills, (pp. 325-344). Charlotte, NC: Information Age Publishing.

Nistor, N., Daxecker, I., Stanciu, D., \& Diekamp, O. (2015). Sense of community in academic communities of practice: Predictors and effects. High Education, 69, 257-273. DOI 10.1007/s10734-014-9773-6.

Panitz, T. (1999). Benefits of cooperative learning in relation to student motivation, in Theall, M. (Ed.) Motivation from within: Approaches for encouraging faculty and students to excel. San Francisco, CA: Josey-Bass publishing.

Redmond, M. A. (2001). A computer program to aid assignment of student project groups. Proceedings of the 32nd Technical Symposium on Computer Science Education (SIGCSE'01), 134-138.

Richards, D. (2009). Designing project-based courses: With a focus on group formation and assessment. $A C M$ Transactions on. Computing Education, 9(1), 2:1-40.

Roberts, T. S., \& McInnerney, J. M. (2007). Seven problems of online group learning (and their solutions). Educational Technology \& Society, 10(4), 257-268.

Robles, M. M. (2012). Executive perceptions of the top 10 soft skills needed in today's workplace. Business Communication Quarterly, 75(4), 453-465.

Russ, J. A., \& Eastep, S. (2013). The perceptions of students toward online learning at a Midwestern university: What are students telling us and what are we doing about it? I.E.: Inquiry in Education, 4(2). Retrieved from http://digitalcommons.nl.edu/ie/vol4/iss $2 / 5$

Sekaran, U. (2003). Research methods for business: A skill building approach (4th ed). Hoboken, NJ: John Wiley \& Sons, Inc.

Swan, K., Shen, J., \& Hiltz, S. R. (2006). Assessment and collaboration in online learning. Journal of Asynchronous Learning Networks, 10(1), 45-62.

Thibodeaux, T. (2016, June 14). 5 soft skills young cybersecurity professionals need to get ahead. Retrieved from http://www.darkreading.com/cloud/5-soft-skills-young-cybersecurity-professionals-need-to-get-ahead/a/did/1325896

Tuckman, B. W, \& Jensen, M. A. C. (1977). Stages of small group development revisited. Group and Organization Studies, 2(4), 419-27.

U.S. Department of Labor. (2014, June). Cybersecurity industry model. Retrieved from www.doleta.gov

U. S. Department of Labor. (2015, December). Occupational outlook handbook. Retrieved from https://www.bls.gov/ooh/computer-and-information-technology/information-security-analysts.htm\#tab-6

Wang, P. (2015, August). Assessment of asynchronous online discussions for a constructive online learning community. International Journal of Information and Education Technology, 5(8), 598-604.

Zaccaro, S., \& Bader, P. (2003). E-leadership and the challenges of leading e-teams: Minimizing the bad and maximizing the good. Organizational Dynamics, 31, 377-387. 